\title{
Point of view: Energy factors for food labelling and other purposes should be derived in a consistent fashion for all food components*
}

\author{
Penelope M. Warwick ${ }^{1} \dagger$ and Janis Baines ${ }^{2}$ \\ ${ }^{1}$ School of Biological Sciences, University of New England, Armidale, Australia \\ ${ }^{2}$ Australia New Zealand Food Authority (ANZFA), Canberra MC, Australia \\ (Received 15 January 1999 - Revised 2 July 2000 - Accepted 7 July 2000)
}

\begin{abstract}
In Australia, the process by which food energy factors are derived for food labelling purposes is under review. One of the questions of international relevance is whether energy factors should be derived using a definition of metabolisable energy (ME) or a definition of net (metabolisable) energy (NME), or some mixture of the two. ME describes the food energy available for heat production and body gains. NME deducts obligatory thermogenesis from ME in an attempt to reflect the food energy that can be converted to ATP energy within the body. Some countries use NME to derive energy factors for novel food ingredients such as sugar alcohols and polydextrose, but continue to use ME for protein, fat, carbohydrate, and alcohol. The present paper puts a case for using a consistent system (ME at the present time) for all food components. Reasons for this include: consistent application to all food components allows valid comparisons between products; food energy values and estimates of energy expenditure (food energy requirements) should be directly comparable; NME does not account for all sources of thermogenesis; differences between ME and NME for sugar alcohols and polydextrose are small in the context of the whole diet; and the ME system does not preclude information about metabolic efficiency being provided as additional information. Any major change to the way in which energy values are expressed (e.g. global adoption of the NME system) merits wide discussion among the human nutrition community. One aim of this present paper is to stimulate this discussion.
\end{abstract}

Energy factors: Food labelling: Metabolisable energy: Net (metabolisable) energy

The energy value of foods is an important issue for consumers (who may be concerned about energy intakes for body weight management), for industry (for product development and labelling) and for the scientific community and health professionals (for educational, clinical and experimental applications).

In Australia, the process by which energy factors for food components are derived for food labelling purposes is under review (Australia and New Zealand Food Authority, 1999). This was prompted by a lack of clear definition of how currently prescribed energy factors were derived, and lack of guidance for establishing factors for novel food components. The key questions posed were: (1) whether energy factors should be derived using a definition of metabolisable energy (ME) or net (metabolisable) energy (NME); and (2) whether energy factors should be derived in a consistent fashion for all food components. The answers to these questions have international relevance.
The consistent application of the ME system is contrary to the use by some countries of ME for conventional nutrients and NME for polyols and polydextrose, while the NME system is not consistently applied anywhere in the world. The present paper puts a case for using a consistent approach to derive energy factors for all food components, conventional and novel, and for using ME as the basis of derivation at the present time. The authors do not preclude the global adoption of the NME system at some time in the future but believe that considerable discussion about the ramifications of doing this is needed.

\section{Terminology}

It is generally accepted that food energy values should reflect the amount of 'available' energy in foods, although opinions differ on the definition of availability. This is a key issue, as the argument for moving to NME (Livesey,

\footnotetext{
Abbreviations: ME, metabolisable energy; NE, net energy; NME, net (metabolisable) energy.

* The views in this paper are personal views, not necessarily the official view of the Australia and New Zealand Food Authority.

$\dagger$ Corresponding author: Dr Penelope Warwick, fax +6126763 3267, email pwarwick@metz.une.edu.au
} 
(1)

Ingested energy $=$ Gross energy $(\mathrm{GE})$

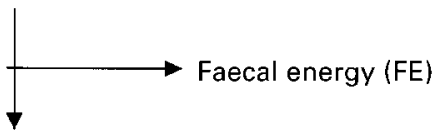

(2)

Digestible energy (DE)

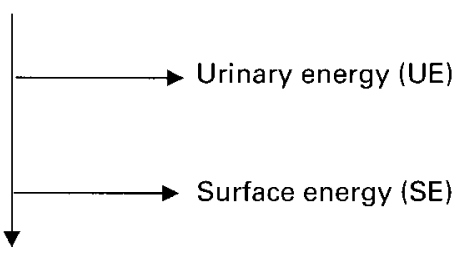

(3) Old metabolisable energy (OME)

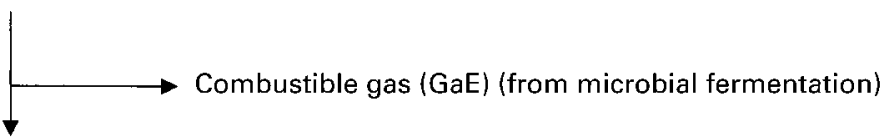

(4) Metabolisable energy (ME)

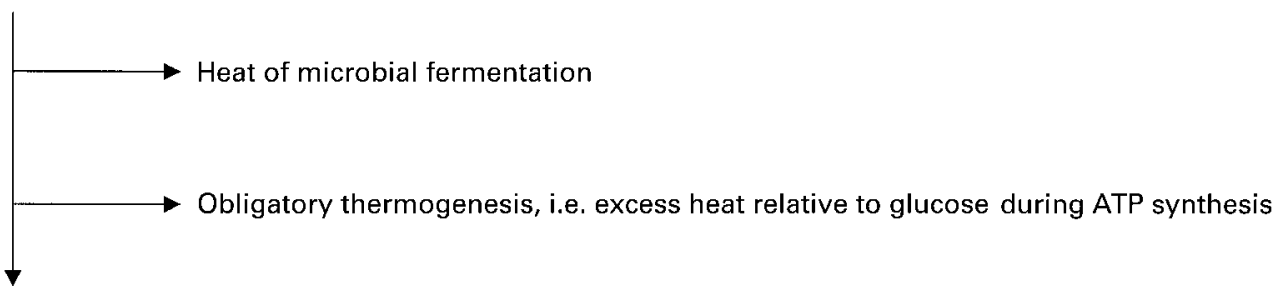

(5) Net (metabolisable) energy (NME)

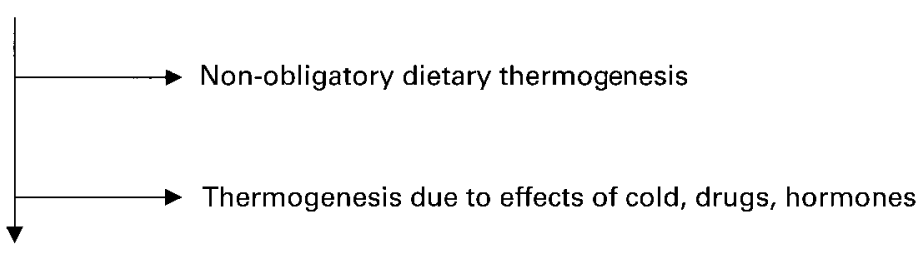

(6) Net energy (NE)

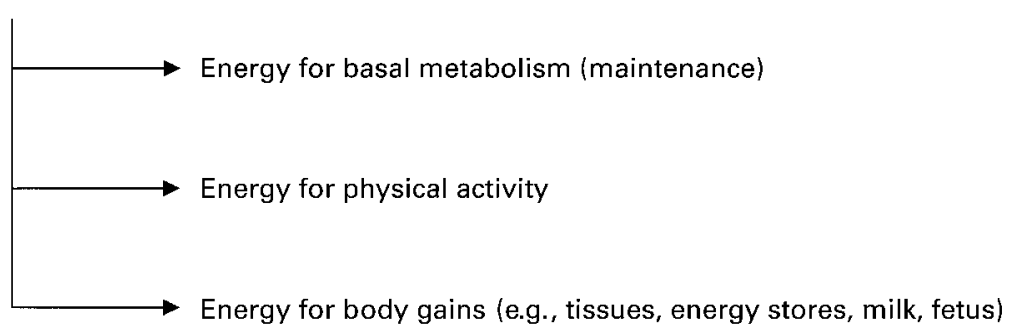

Fig. 1. Overview of food energy utilisation (adapted from FASEB, 1994).

$1991 a, 1992)$ rests on a re-definition of what food energy should be available for.

Fig. 1 sets out an overview of food energy utilisation in the body. This figure shows that some of the ingested energy is lost in faeces and urine, with small amounts lost in hair, skin, and other secretions (surface energy). Point 3 in Fig. 1 is the traditional definition of ME (Merrill \& Watt, 1955). It is now known that some of the energy that reaches the large intestine undergoes microbial fermentation with subsequent increase in microbial mass (British Nutrition Foundation, 1990; Livesey, 1992; Food and Agriculture Organization/World Health Organization, 1998). The 
energy content of the microbial mass is lost as faecal matter, and is accounted for in faecal energy losses. Shortchain fatty acids liberated during the fermentation process are absorbed, providing a source of energy. Heat and combustible gases are also produced and represent energy lost to absorption. However, the heat of fermentation is not an energy loss to the whole body as man is a warm-blooded animal and heat produced contributes to thermoregulation.

Point 4 in Fig. 1 reflects the ingested energy minus that lost in faeces, urine, surface and combustible gases, and has been called ME for the present paper. This definition of ME is similar to that of others (Schutz, 1984; Sentko, 1992, cited in FASEB, 1994) and describes the amount of energy available for total (whole body) heat production and for body gains (tissue or milk synthesis, energy stores) (Allison \& Senti, 1983, cited in FASEB, 1994). It includes energy available for heat of fermentation which is heat produced in the colon and therefore in the whole body. Some other definitions of ME have excluded energy available for heat of fermentation (Bernier \& Pascal, 1990; FASEB, 1994).

However, it is ATP produced during oxidation of organic substrates that is ultimately used for physical and metabolic work, and different substrates produce different amounts of ATP per kJ energy absorbed (Livesey, 1984; Flatt, 1985). Some substrates are converted to ATP less efficiently than others, or require ATP to be used during obligatory metabolic processes, with consequent heat production. Whether this heat is 'wasted' (Brown et al. 1993) depends on whether heat for thermoregulation is considered useful or not.

Heat produced during the processing of ingested nutrients contributes to the component of total daily energy expenditure called thermogenesis. Thermogenesis is defined as energy expenditure that cannot be attributed to basal metabolism or to physical activity. It is stimulated by food (dietary thermogenesis), cold, drugs and hormones. Dietary thermogenesis is usually considered in two parts, obligatory and facultative (Jequier, 1983; Ravussin \& Swinburn, 1993). Obligatory thermogenesis is the heat produced during obligatory metabolic processing of ingested nutrients, such as the storage of glucose as glycogen, fatty acids as triacylglycerol, and the catabolism of amino acids. Facultative thermogenesis is the heat produced over and above what would be expected from the obligatory processes, and is thought to be under hormonal control (Ravussin \& Swinburn, 1993).

Point 5 in Fig. 1 represents the food energy available to the body after the heat produced during fermentation and obligatory thermogenesis has been deducted from ME. This point has been variously called net energy (NE) (Livesey, 1991a; Brown et al. 1993), NME (Livesey, 1993), or NE for maintenance (Livesey, 1995a). For the present paper it has been called NME and is taken to describe the amount of food energy that is biologically useful in ATP equivalents (G Livesey, unpublished, results). However, this is not strictly true as NME does not deduct heat produced during facultative and other types of thermogenesis, which is food energy that is not available for ATP production.

Point 7 on Fig. 1 is the food energy available after heat losses from both obligatory and non-obligatory dietary thermogenesis have been deducted, as well as thermogenesis due to effects of cold, drugs (e.g. caffeine, smoking) or hormones. This point has been called NE for the present paper. This NE is a more valid estimate of the amount of energy available for ATP production than NME.

\section{Energy factors for food labelling: best derived using metabolisable energy or net (metabolisable) energy?}

The use of NME for food labelling is favoured by Livesey and his co-workers, and the topic has been widely reviewed (Livesey, 1990, 1991a,b, 1992, 1993, 1995b; Brown et al. 1993; G Livesey, unpublished results). It has long been known that dietary thermogenesis due to protein is higher than that due to fat and carbohydrate. Stoichiometric calculations show that about $20 \%$ absorbed protein energy is used during the obligatory metabolic processes of urea synthesis and gluconeogenesis following the catabolism of amino acids (Livesey, 1984; Flatt, 1985), suggesting that protein is an inefficient source of energy. Whole-body calorimetry has confirmed that total energy expenditure (and therefore food energy need) is higher with highprotein than with high-glucose diets (Dauncey \& Bingham, 1983). Short-chain fatty acids produced by fermentation of carbohydrates and sugar alcohols in the large intestine are also an inefficient source of energy, as they generate about $15 \%$ less ATP per kJ energy absorbed than from the direct oxidation of the same amount of energy absorbed as glucose (British Nutrition Foundation, 1990; Livesey, 1992, 1993; FASEB, 1994).

Thus, foods or diets that are high in protein, fermentable carbohydrates or sugar alcohols could be considered less 'fattening' than foods or diets low in those components. In this case it would seem to make sense to reduce the energy values for these components accordingly. This is what is proposed by using the NME system (Livesey, 1991a). However, while we agree that inefficiencies of energy metabolism are physiologically important and interesting, we do not agree that this information should be incorporated globally into energy factors used for food labelling and public education purposes at the present time. Reasons for this point of view are now outlined.

\section{Reasons for point of view}

Food energy values should be directly comparable with estimates of food energy expenditure (food energy requirements) and with values in food tables. The main aims of food labelling are to inform the consumer of the composition of food and to assist them in the selection of a healthy diet (Food and Agriculture Organization/World Health Organization, 1998). Providing daily benchmarks (e.g. guideline daily amounts) on food labels together with information on the quantity of nutrients in the food can help make nutrition information more accessible to consumers (Sadler, 1998). We believe that the information most useful to consumers, and most easily used by industry and health professionals, is that which indicates how much food energy is available to the body in relation to food energy requirements, or dietary reference intakes for energy. This information should also be comparable with information in food composition tables. 
The food energy requirements of healthy people are currently defined as the level of ME in food that will balance energy expenditure plus additional needs for growth, pregnancy and lactation (Food and Agriculture Organization/World Health Organization/United Nations University, 1985; Warwick, 1990; National Health and Medical Research Council, 1991). For most adults, estimates of energy requirements are derived from measures of energy expenditure and are expressed in terms equivalent to the $\mathrm{ME}$ at point 4 in Fig. 1 . We therefore consider that this definition is appropriate for the derivation of energy factors for food labelling purposes.

We recognise that estimates of energy requirements in most individuals are unlikely to be better than $\pm 10 \%$, and that, despite limitations of current methods for deriving energy values for foods and diets (Livesey, 1991 b, 1995b), the energy content of the diet can be estimated more accurately than energy requirements ( $G$ Livesey, unpublished results). However, the accuracy of food intake measurements limits the accuracy of calculated food energy intakes so that general energy conversion factors need not be as precise (Livesey, 1991a). In addition, energy factors used for food labelling can never accurately reflect the energy available from foods consumed as part of whole diets, because of effects of dietary composition on the digestibility of (and therefore the availability of energy from) the various macronutrients (Steinhart et al. 1992; Livesey, 1995a,b; Baer et al. 1997; Brown et al. 1998).

As a matter of principle, energy factors used for food labelling and other purposes should be compatible with the standards against which they are compared. Of course, it would be possible to revise both the data in food tables and the way in which dietary recommendations for energy are expressed to fit an NME system. However, any major change to the way in which energy values are expressed is of international concern, and has not been widely discussed. We question the value in adopting a global NME system in which theoretical amounts for obligatory thermogenesis would be deducted from both the energy values of foods and the estimate of energy expenditure from which recommendations for energy intake are derived, especially since energy expenditure is an experimentally measurable quantity.

Any system used should be consistent across foods and food components to allow valid inter-product comparisons. We believe that the system adopted to derive energy factors (whether ME or NME) should be applied consistently to all nutrients and food components, including novel compounds of the future. This is contrary to the current situation in some countries where NME is used for sugar alcohols and polydextrose but not for the conventional macronutrients (Van Es, 1991; FASEB, 1994).

Livesey has argued that the NME system should also be adopted for unavailable carbohydrates (Livesey, 1992) and protein (Livesey, 1991a), as the obligatory energy losses for these nutrients are significant. For example, the energy factors would be approximately $16.7 \mathrm{~kJ} \mathrm{ME} / \mathrm{g}$ or approximately $13.5 \mathrm{~kJ} \mathrm{NME} / \mathrm{g}$ for protein (British Nutrition Foundation, 1990), approximately $12 \mathrm{~kJ} \mathrm{ME} / \mathrm{g}$ or approximately $10 \mathrm{~kJ} \mathrm{NME} / \mathrm{g}$ for fully-fermentable unavailable carbohydrates such as resistant starch (Livesey, 1991b), and approximately $8 \mathrm{~kJ} \mathrm{ME} / \mathrm{g}$ or approximately $6.8 \mathrm{~kJ} \mathrm{NME} / \mathrm{g}$ for unavailable carbohydrates in a mixed Western diet (British Nutrition Foundation, 1990; Livesey, 1995b). There has been no suggestion to date that NME should be used to derive factors for fats, alcohol, or the different types of available carbohydrate, even though some (albeit small) obligatory energy losses occur during the storage of glucose as glycogen and fatty acids as triacylglycerol (Livesey, 1984; Flatt, 1985). There is also some evidence that different available carbohydrates have different thermic effects (Schwartz et al. 1992), although it is not clear whether these differences are due to obligatory or to facultative processes. Alcohol energy may also be inefficiently utilised (Lieber, 1991; Stock, 1996), although this is controversial (Prentice, 1996).

If the NME system was consistently adopted for all nutrients and food components the ramifications for the human nutrition industry would be large because of the quantities of protein and unavailable carbohydrate consumed. For example, if $100 \mathrm{~g}$ protein, $50 \mathrm{~g}$ resistant starch and $20 \mathrm{~g}$ mixed NSP were consumed daily, the total energy intake would be approximately $450 \mathrm{~kJ} / \mathrm{d}$ lower using NME than ME values, or a difference of about $6 \%$ of an energy expenditure of $8000 \mathrm{~kJ} / \mathrm{d}$. For this scenario, energy intakes derived using NME factors would definitely not be comparable with current recommendations for energy intake $(8000 \mathrm{~kJ} \mathrm{ME} / \mathrm{d})$ and the latter would have to be revised to $7550 \mathrm{~kJ} \mathrm{NE} / \mathrm{d}$ for compatibility.

Another reason for applying a consistent approach across all nutrients and food components is to allow valid comparisons between products of mixed composition, especially in the future as more novel food ingredients are developed. In the scenario illustrated in Table 1, consistent application of both ME and NME systems shows that product A contains slightly more energy than product

Table 1. Comparison of the energy contents of two products calculated in different ways

\begin{tabular}{|c|c|c|c|c|}
\hline \multirow[b]{2}{*}{ Product } & \multirow[b]{2}{*}{ Nutrient composition } & \multicolumn{3}{|c|}{ Energy content $(\mathrm{kJ} / \mathrm{kg})^{*}$} \\
\hline & & ME & NME & Partial NME† \\
\hline $\begin{array}{l}\text { A. Modified ice } \\
\text { confection }\end{array}$ & $\begin{array}{l}41 \mathrm{~g} \text { fat } / \mathrm{kg}, 291 \mathrm{~g} \text { hypothetical novel } \\
\text { carbohydrate } / \mathrm{kg} \text { (replacing } 92 \mathrm{~g} \text { fat and } \\
199 \mathrm{~g} \text { sugar } / \mathrm{kg} \text { in normal ice confection) }\end{array}$ & 4190 & 3460 & 3610 \\
\hline B. Cottage cheese & $177 \mathrm{~g}$ protein $/ \mathrm{kg}, 12 \mathrm{~g}$ fat $/ \mathrm{kg}, 19 \mathrm{~g}$ sugar $/ \mathrm{kg}$ & 3750 & 3130 & 3750 \\
\hline
\end{tabular}

$\mathrm{ME}$, metabolisable energy; NME, net (metabolisable) energy.

* Energy content calculated factorially using energy factors of: $17 \mathrm{~kJ}$ ME/g or $13.5 \mathrm{~kJ}$ NME/g for protein, $16 \mathrm{~kJ}$ ME and NME/g for sugars, $37 \mathrm{~kJ}$ ME and NME/kg for fats and $12 \mathrm{~kJ} \mathrm{ME} / \mathrm{g}$ or $10 \mathrm{~kJ} \mathrm{NME} / \mathrm{g}$ for the novel carbohydrate.

† Partial NME calculated by applying the NME factor to the novel carbohydrate and ME factors to the other components. 
B. If NME factors are applied only to the (hypothetical but realistic) novel carbohydrate and not to the other nutrients, product $A$ appears (incorrectly) to contain less energy than product $\mathrm{B}$.

The net (metabolisable) energy system is incomplete as it deducts only obligatory and not other types of thermogenesis. If the aim of using NME is to depict the amount of ATP available for metabolic and physical work, we believe that all types of thermogenesis should be deducted and that NE should be used. However, other types of thermogenesis are too variable to quantify in the context of individual food energy values and it would be almost impossible to deduct them with any certainty. The efficiency of energy metabolism in the whole body is influenced by numerous factors, including the plane of nutrition (overfed or underfed), nutrient balance of the diet, smoking, caffeine and other drugs, hormones, environmental temperature and other factors (Garrow, 1978; Warwick, 1990; Ravussin \& Swinburn, 1993). In terms of the whole body, we question the distinction between NE and NME as it (incorrectly) implies a clear separation between obligatory and non-obligatory thermogenesis.

There are other ways of incorporating the concept of efficiency into the system without adjusting food energy values. We recognise that many people in Western countries are interested in knowing which food components or dietary patterns or lifestyle factors are least fattening, and have no doubt that such information is of scientific interest and importance. However, we believe that the concept of metabolic efficiency may be better handled 'in a package' by health professionals or in educational material as part of the process of giving dietary or health advice, as is currently the case. For example, advice may be given that stopping smoking may reduce metabolic rate; that losing weight reduces food energy needs (for the same level of activity); that cold temperatures may increase metabolic rate; that some drugs can change metabolic rate; that energy from dietary protein is less fattening than the same amount of energy from carbohydrate or fat. The accounting of inefficiencies due to obligatory thermogenesis in a food label value singles out only one of a myriad of factors that affect metabolic efficiency in the whole body.

The metabolisable energy system is consistently used around the world, except for sugar alcohols and polydextrose, and the difference between metabolisable energy and net (metabolisable) energy for these components is small in the context of the whole diet. The use of ME for deriving food energy factors for food labelling purposes is consistent with current international agreements for the conventional macronutrients (Codex Alimentarius Commission, 1993). There are no Codex factors for sugar alcohols and polydextrose at present. While committees in several countries have adopted NME factors for these compounds, there is no international agreement on the actual factors ascribed. For example, FASEB (1994) ascribed individual values to each sugar alcohol while the European Community adopted an average value of $10 \mathrm{~kJ} / \mathrm{g}$ for all sugar alcohols (Van Es, 1991). The difference between ME and NME for these fermentable compounds is also very small in the context of the whole diet. For sugar alcohols, the difference between ME and NME factors ranges from approximately 0.3 to $2.5 \mathrm{~kJ} / \mathrm{g}$ (re-calculation of data from Livesey (1992)), while for polydextrose the difference is approximately $1 \mathrm{~kJ} / \mathrm{g}$ (ME $>\mathrm{NE}$ ). At the upper recommended intake of $20 \mathrm{~g}$ sugar alcohol daily (Van Es, 1991), or with occasional intakes of polydextrose as high as $70 \mathrm{~g} / \mathrm{d}$ (G Livesey, unpublished results) total energy intake would range from 6 to $70 \mathrm{~kJ} / \mathrm{d}$ higher using ME than NME, a difference of less than $1 \%$ of a total intake of $8000 \mathrm{~kJ} \mathrm{ME} / \mathrm{d}$.

Overall, we conclude that whatever system is used to derive energy factors for sugar alcohols and polydextrose (ME or NME) the error is likely to be very small as a proportion of daily intake, and unlikely to be of importance to body weight.

\section{Summary}

In summary, we propose that energy factors for food labelling and other purposes be derived in a consistent fashion for all food components, conventional and novel. For the present time we propose that these energy factors be derived using the definition of ME listed at point 4 on Fig. 1, i.e. the amount of energy available for whole-body heat production and for body gains. We recognise that the future may (or may not) hold a global move toward adoption of NME for all food components, but this has not yet been widely discussed.

\section{References}

Allison RG \& Senti FR (1983) A Perspective on the Atwater System of Food Energy Assessment. (Prepared for the US Department of Agriculture under USDA Grant Agreement No. 59-3198-2-45 by the Life Sciences Research Office, Federation of the American Societies for Experimental Biology) Bethesda, MD: Special Publications Office, FASEB.

Australia and New Zealand Food Authority (1999) Derivation of Energy Factors: Full Assessment Report Proposal P177. Canberra: Australia New Zealand Food Authority.

Baer DJ, Rumpler WV, Miles CW \& Fahey GC (1997) Dietary fibre decreases the metabolizable energy content and nutrient digestibility of mixed diets fed to humans. Journal of Nutrition 127, 579-586.

British Nutrition Foundation (1990) Energy values of complex carbohydrates. In Complex Carbohydrates in Foods. The Report of the British Nutrition Foundation's Task Force, pp. 55-56. London: Chapman Hall.

Brown JC, Faulks RM \& Livesey G (1993) Developing an international food energy system. Food Technology International 29-33.

Brown JC, Livesey G, Roe M, Faulks R, Poppitt S, Wilkinson J \& Elia M (1998) Metabolizable energy of high non-starch polysaccharide-maintenance and weight-reducing diets in men: experimental appraisal of assessment systems. Journal of Nutrition 128, 986-995.

Bernier JJ \& Pascal G (1990) The energy value of polyols (sugar alcohols). Medicine et Nutrition 26, 221-238.

Codex Alimentarius Commission (1993) Codex Guidelines on Nutrition Labelling. Rome: FAO/WHO.

Dauncey MJ \& Bingham SA (1983) Dependence of 24 h energy expenditure in man on the composition of the nutrient intake. British Journal of Nutrition 50, 1-13.

FASEB (1994) The Evaluation of the Energy of Certain Sugar Alcohols Used as Food Ingredients. Bethesda, MD: Life Sciences Research Office. 
Food and Agriculture Organization/World Health Organization (1998) Carbohydrates in Human Nutrition. FAO Food and Nutrition Paper No. 66. Rome: FAO.

Food and Agriculture Organization/World Health Organization/ United Nations University (1985) Energy and protein requirements. WHO Technical Report Series No. 724. Geneva: WHO.

Flatt JP (1985) Energetics of intermediary metabolism. In Substrate and Energy Metabolism in Man, pp. 58-69 [JS Garrow and D Halliday, editors]. London: John Libbey.

Garrow JS (1978) Energy Balance and Obesity in Man. North Holland: Elsevier.

Jequier E (1983) Thermogenic responses induced by nutrients in man: their importance in energy balance regulation. In Nutritional Adequacy, Nutrient Availability and Needs, pp. 26-44 [J Mauron, editor]. Basel: Birkhauser Verlag.

Lieber CS (1991) Perspectives: do alcohol calories count? American Journal of Clinical Nutrition 54, 976-982.

Livesey G (1984) The energy equivalents of ATP and the energy values of food proteins and fats. British Journal of Nutrition 51, $15-28$.

Livesey G (1990) Energy values of unavailable carbohydrates and diets: an inquiry and analysis. American Journal of Clinical Nutrition 51, 617-637.

Livesey G (1991a) Determinants of energy density with conventional foods and artificial feeds. Proceedings of the Nutrition Society 50, 371-382.

Livesey G (1991b) The energy value of carbohydrate and fibre for man. Proceedings of the Nutrition Society of Australia 16, 7988.

Livesey G (1992) The energy value of dietary fibre and sugar alcohols for man. Nutrition Research Reviews 5, 61-84.

Livesey G (1993) Comments on the methods used to determine the energy values of carbohydrates: dietary fibre, sugar alcohols and other bulking agents. International Journal of Food Science and Nutrition 44, 221-241.

Livesey G (1995a) The impact of complex carbohydrates on energy balance. European Journal of Clinical Nutrition 49, Suppl. 3, S89-S96.

Livesey G (1995b) Metabolisable energy value of macronutrients. American Journal of Clinical Nutrition 62, Suppl., 1135S$1142 S$.

Merrill AI \& Watt BM (1955) Energy values of foods: basis and derivation. Agriculture Handbook no. 74. Washington, DC: US Government Printing Office.

National Health and Medical Research Council (1991) Recommended Dietary Intakes for Use in Australia. Canberra: Australian Government Publishing Service.

Prentice AM (1996) Do calories from alcohol contribute to obesity? British Nutrition Foundation Nutrition Bulletin 21, 45-48.

Ravussin E \& Swinburn BA (1993) Energy metabolism. In Obesity: Theory and Therapy, pp. 97-123 [AJ Stunkard and TA Wadden, editors]. New York, NY: Raven Press.

Sadler MJ (1998) Making nutrition labelling more accessible for consumers. British Nutrition Foundation Nutrition Bulletin $\mathbf{2 3}$ 142-149.

Schutz Y (1984) Glossary of energy terms and factors used for calculations of energy metabolism in human subjects. In Human Energy Metabolism: Physical Activity and Energy Expenditure Measurements in Epidemiological Research Based upon Direct and Indirect Calorimetry, Euro-Nut Report 5. Report of an EC Workshop, October 24-26, 1984, pp. 161-181 [AJH Van Es editor]. Wageningen: Euro-Nut.

Schwartz JM, Schutz Y, Piolino V, Schneider H, Felber JP \& Jequier E (1992) Thermogenesis in obese women: effect of fructose vs glucose added to a meal. American Journal of Physiology 262, E394-E401.

Sentko A (1992) Energetic (Caloric) Utilization of Isomalt (Palatinit $\AA$ ). (Prepared for Sudzucker AG, Mannheim/Oschenfurt Geschaftsbereich Palatinit, Mannheim, Federal Republic of Germany.)

Steinhart AH, Jenkins DJA, Mitchell S, Cuff D \& Prokipchuck EJ (1992) Effect of dietary fiber of total carbohydrate losses in ileostomy effluent. Journal of Gastroenterology 87, 48-54.

Stock MJ (1996) Do calories from alcohol contribute to obesity? British Nutrition Foundation Nutrition Bulletin 21, 49-53.

Van Es AJH (1991) Dietary energy density on using sugar alcohols as replacements for sugars. Proceedings of the Nutrition Society 50, 383-390.

Warwick PM (1990) Predicting food energy requirements from estimates of energy expenditure. In Recommended Nutrient Intakes Australian Background Papers, pp. 295-320 [AS Truswell, IE Dreosti, RM English, IHE Rutishauser and N Palmer, editors]. Sydney: Australian Professional Publications. 